\title{
Um mundo indiferente: idiotia e insignificância em 0 Pequeno Quinquin de Bruno Dumont
}

\author{
ROGÉRIO DE ALMEIDA \\ MARCOS BECCARI \\ CESAR ZAMBERLAN
}

Resumo

Com base na série televisiva O Pequeno Quinquin (P’TIT QUINQUIN, 2014), de Bruno Dumont, este artigo propõe uma reflexão, à luz da filosofia trágica (Nietzsche, Rosset), acerca da indiferença do mundo expressa pelas noções de idiotia e insignificância. Após uma breve contextualização da obra cinematográfica de Bruno Dumont, delineamos uma interpretação possível sobre a série elencada, equacionando indiferença mundana e aprovação da vida. Observamos, por fim, que a idiotia e a insignificância se manifestam em $\mathrm{O}$ Pequeno Quinquin não como uma exceção à normalidade, mas como expressão do mundo humano.

Palavras-chave: Indiferença, idiotia, filosofia trágica 


\title{
An indifferent world: idiocy and insignificance in the "P'tit Quinquin" of Bruno Dumont
}

\author{
ROGÉRIO DE ALMEIDA \\ MARCOS BECCARI \\ CESAR ZAMBERLAN
}

\section{Abstract}

Based on the television series Li'l Quinquin (P’TIT QUINQUIN, 2014), by Bruno Dumont, this article proposes a preamble, under the bias of the tragic philosophy (Nietzsche, Rosset), about the indifference of the world expressed by the notions of idiocy and insignificance. After a brief contextualization of the cinematographic work of Bruno Dumont, we delineate a possible interpretation about the chosen series, equating worldly indifference and life approval. We observe, finally, that idiocy and insignificance are manifested in Li'l Quinquin not as an exception to normality, but as an expression of the human world. 


\title{
Un mundo indiferente: la idiotez y la insignificancia en "P'tit Quinquin" de Bruno Dumont
}

\author{
ROGÉRIO DE ALMEIDA \\ MARCOS BECCARI \\ CESAR ZAMBERLAN
}

\section{Resumen}

Basado en la serie televisiva P'tit Quinquin (2014), de Bruno Dumont, este artículo propone una reflexión, a la luz de la filosofía trágica (Nietzsche, Rosset), sobre la indiferencia del mundo expresa por las nociones de idiotez y insignificancia. Después de una breve contextualización de la obra cinematográfica de Bruno Dumont, diseñamos una interpretación posible sobre la serie elegida, asociando indiferencia mundana y la aprobación de la vida.

Ponderamos, al final, que la idiotez y la insignificancia se manifiestan en P'tit Quinquin (2014), no como una excepción de la normalidad, sino como expresión del mundo humano. 


\section{Introdução}

O objetivo deste artigo é tratar, sob o viés da filosofia trágica (Nietzsche, Rosset), da indiferença do mundo expressa pelas noções de idiotia e insignificância. Para pensar tal questão, convocamos a série televisiva $O$ Pequeno Quinquin (P'TIT QUINQUIN, 2014), do diretor francês Bruno Dumont. Como a obra em questão não é tradicionalmente categorizada como "cinematográfica", cumpre traçarmos, ainda que brevemente, algumas considerações metodológicas.

Nos últimos anos, para além dos campos tradicionais da história, da teoria e da crítica cinematográficas, foi possível vislumbrar a difusão de novas abordagens que exploram não tanto as questões específicas da linguagem cinematográfica, e sim, sobremaneira, certos aspectos conjunturais (sejam tecnológicos, discursivos ou socioculturais) que permeiam historicamente o cinema. É o caso dos "Estudos Fílmicos" (REIA-BAPTISTA, 2005) - ou Cinema Studies, na designação norte-americana -, que se propõem a desenvolver, sob perspectivas diversas, estudos de casos bem delimitados: películas isoladas ou em conjunto (como cinematografias nacionais ou autorais). Sob esse prisma, o objeto fílmico deixa de ser encarado como meio estritamente narrativo (BORDWELL, 1996) e passa a ser contemplado como elemento de processos mais abrangentes de mediação cultural. ${ }^{1}$

É nesse contexto de reflexão que nos é permitido redimensionar o alcance do objeto fílmico, isto é, considerando seu atual espectro de veiculação audiovisual: o cinema, a televisão e a internet (sem ignorar, é claro, as variáveis condicionantes entre tais mídias). Pois o que caracteriza o objeto fílmico, seja em curtas-metragens ou em séries televisivas, continua sendo 
a presença de códigos cinematográficos (como encadeamento narrativo, enquadramento, cortes etc.); o que parece ganhar força e repercussão hoje, porém é o modo pelo qual as narrativas audiovisuais "[...] desorganizam e reorganizam as práticas culturais" (SOARES, 2016, p. 83).

Entretanto, diferentemente das ênfases usualmente adotadas nos estudos fílmicos (quais sejam, aquelas adjacentes aos estudos culturais), o que aqui nos interessa é menos o "discurso" que permeia dada película e mais o pensamento que a agencia filosoficamente e que nela adquire alguma expressão. Em outros termos, sendo o filme uma forma de mediação cultural, aquilo que ele "diz" não importa tanto quanto o pensamento que se abre a partir dele. ${ }^{2}$ Significa que o presente estudo pode ser situado no limiar entre os estudos fílmicos - que nos "autoriza" partir de uma série televisiva como narrativa audiovisual - e uma hermenêutica fílmica - que nos possibilite mirar, a partir de uma série televisiva, em direção a uma interpretação filosófica.

Posto isso, colocamo-nos a tarefa de testar uma experimentação: buscar perceber algumas formas de desencadeamento do pensamento trágico em $O$ Pequeno Quinquin (2014). Não se trata, cumpre insistir, de inventariar as possíveis referências que amparam tal obra de Bruno Dumont; queremos propor, o que nos parece ser um pouco diferente, uma interpretação que nos possibilite encontrar, acompanhados, uma perspectiva de afirmação da vida mesmo em seus aspectos mais duros e estranhos.

\section{Uma aproximação à obra cinematográfica de Bruno Dumont}

A parceria entre redes de televisão e diretores de cinema tende a ser bastante positiva, ainda que muitos hesitem - e insistam - em ver a televisão como algo não necessariamente sério ou menor que o cinema. São vários os exemplos nestas últimas décadas de obras primas, sejam longas-metragens ou séries, que resultaram dessa parceria. $\mathrm{O}$ maior de todos os exemplos talvez seja, e não pela extensão, os quatorze episódios nos quais Rainer Werner Fassbinder adaptou Berlin Alexanderplatz, livro de Alfred Döblin. Monumental, a obra é, juntamente com os telefilmes de Roberto Rossellini, com o apoio da RAI (Radiotelevisione Italiana), exemplos que atenuaram e ajudaram a dissolver nos anos 1960 as fronteiras rígidas entre os meios. 
Existia e ainda existe um pensamento crítico-formalista que defende o argumento de que Fassbinder e Rossellini, e também Godard, cada qual ao seu modo, usaram a televisão para fazer cinema. Para esses, um meio maior, mais próximo do universo artístico. A discussão é longa e os argumentos variados e abrangentes, porém as próprias declarações dos cineastas (FASSBINDER, 1988; CRUCHINHO, 2007) servem para mostrar que, ainda que fosse possível estabelecer algumas distinções em relação aos meios e aos protocolos de recepção da obra e, sobretudo, em relação ao receptor, a forma narrativa sobressaía, fosse ela recebida na tela grande, e dentro daquilo que Hugo Mauerhofer (apud XAVIER, 1983, p. 375-380) denominou de experiência cinema, fosse recebida na tela pequena, com todas as distrações possíveis; fosse por um público mais erudito, associado em tese ao cinema, ou por um público mais em busca de entretenimento, associado em tese à televisão.

A questão da recepção e do público assume novos contornos com os avanços e a popularização da tecnologia, com a entrada do digital e dos aparelhos de televisão de LCD e depois de LED, cujo formato widescreen (tela panorâmica) propicia melhores condições de fruição, diminuindo sensivelmente a distância entre as condições de recepção em uma sala de cinema e em um ambiente doméstico. Por outro lado, com streamings como Netflix (que não trazem intervalos publicitários) e compartilhamento de filmes em formato digital, o acesso a determinadas obras, antes exclusivas de cineclubes ou cinemas, foi democratizado.

Se há duas, três ou cinco décadas, era quase que inviável assistir cinema em casa, em razão da discrepância entre a película projetada nas salas de cinema e a qualidade da tela de tubo, atualmente não só as condições são próximas (tela panorâmica e grande, qualidade de imagem e som etc.) para os espectadores como também para os produtores. A película foi substituída em larga medida pelo formato digital e, mesmo quando não o foi, não há mais a distância de outrora.

Esses aspectos tecnológicos, associados à expansão das operadoras a cabo e assunção dos streamings, além de outros meios digitais, pagos ou partilhados de maneira gratuita entre computadores (via torrent, por exemplo), ocasionaram também maior diversidade nas obras desenvolvidas. Esmorece a lógica que ditava a produção para as massas, com seu inevitável prejuízo de variação estética e temática (fator quantitativo), e entra em cena a segmentação de públicos, o que possibilita 
diversidade estética e temática, e abre nichos para que determinadas obras sejam veiculadas, como é o caso de $O$ Pequeno Quinquin (2014), série que é o objeto deste ensaio.

$O$ Pequeno Quinquin - pronuncia-se Cancã - estreou em 2015 nos cinemas brasileiros com suas quase três horas e meia de duração, depois de ser exibido no ano anterior pela TV francesa, em quatro episódios, atingindo mais de 1 milhão e 300 mil telespectadores (LANLO, 2015). Foi indicado em Cannes para o Globe de Cristal como "Melhor filme televisivo ou melhor série", além de ganhar três prêmios em festivais de cinema, incluindo o de São Paulo (IMDB, 2014).

Bruno Dumont, o diretor de O Pequeno Quinquin (2014), iniciou sua carreira de cineasta em 1997, com A Vida de Jesus, um filme que expõe a crueldade e a violência humanas em meio a um ambiente rural, o pequeno povoado de Bailleul, terra natal do diretor, por meio do jovem Freddy, seus amigos, sua namorada e a presença indesejada do argelino Kader. O filme ganhou a Câmera de Ouro do Festival de Cannes, projetando o diretor no cenário internacional.

Seu segundo filme, A Humanidade (1999), ambienta-se no mesmo cenário bucólico e se desenvolve com a mesma lentidão contemplativa, mas introduz um elemento novo, posteriormente resgatado em $O$ Pequeno Quinquin (2014), que é a presença do investigador de polícia deslocado, inábil, incapaz de compreender o mal. Pharaon de Winter encontra o corpo violentado de uma menina de onze anos e, enquanto investiga o crime, mantém sua vida rotineira, andando de bicicleta, cuidando de sua horta e desejando Domino, uma amiga operária que namora Joseph, motorista de ônibus. Caracterizado como um idiota, o protagonista se mostra incapaz de compreender a humanidade e suas motivações, seja para a violência ou para o sexo. No entanto, embora a humanidade apareça sob o signo da insignificância, Pharaon de Winter demonstra-se curioso e compassivo, cheirando os suspeitos, observando Domino e Joseph fazendo sexo, abraçando o culpado e renunciando a qualquer tentativa de encontrar um sentido ou nutrir alguma esperança em relação ao que é humano.

Os filmes seguintes consolidam a assinatura de Bruno Dumont, tanto em seu estilo de filmar, com o uso de não atores e predileção por cenas lentas, silenciosas e contemplativas, quanto pela temática, que apequena o homem em ambientes naturais e amplos, o mostra indiferente diante do mal, incapaz de compreender as relações e motivações humanas, 
envolto em crueldade e incompreensão, por vezes tocado por um misticismo sem deus, por uma metafísica sem transcendência, uma espiritualidade que se esgota na contemplação do mundo, na adesão ao presente, sem nenhuma outra ambição. Assim, se em Twentynine Palms (2003) e Flandres (2006) predomina a temática da violência, do mal e da crueldade, em O Pecado de Hadewijch (2009) e Fora de Satã (2011) aflora a questão religiosa, com a fé, o milagre e o pecado deslocados da transcendência metafísica e encarnados numa metafísica imanente que faz do mundo a única realidade possível. Assim, em O Pecado de Hadewijch, Céline é retirada do convento por excesso de fé, retornando ao mundo para que encontre sua vocação, enquanto em Fora Satã um homem místico, entre o divino e o demoníaco, opera milagres por meio de atos concretos, como atirar no padrasto que abusa de sua enteada, ou exorcizar uma viajante por meio de uma relação sexual.

Antes de $O$ Pequeno Quinquin (2014), Dumont filma Camille Claudel 1915 (2013), retratando o momento em que a escultora, interpretada por Juliette Binoche, é internada contra sua vontade em um asilo psiquiátrico mantido por religiosas. Mantendo sua escritura cinematográfica, Dumont explora minuciosamente os menores gestos e movimentos de Claudel para mergulhar em sua condição psíquica, sem em momento algum julgá-la. Essa indiferença quanto à possibilidade de sua loucura revela, em contraponto, a mesma indiferença quanto à lucidez. É um filme que se enfileira com os demais ao mostrar uma humanidade cujas ações (violentas, sexuais, místicas etc.) são sempre incompreensíveis.

\section{Uma possibilidade de compreensão de O Pequeno Quinquin}

Ora, precisamente a maioria dos homens suporta a vida sem resmungar demais, e com isso acredita no valor da existência, mas precisamente porque cada qual só quer e afirma a si mesmo, e não sai de si como aquelas exceções: todo extrapessoal, para eles, ou não é perceptível ou o é, no máximo, como uma fraca sombra. Portanto, somente nisto repousa o valor da vida para o homem comum, cotidiano: ele se dá mais importância do que ao mundo. (NIETZSCHE, 1983, p. 96-97).

Embora a concepção de trágico proceda das tragédias gregas, adotaremos suas implicações filosóficas desenvolvidas a partir de Nietzsche, que associou o pensamento trágico 
à alegria e à aprovação incondicional da vida (HIERRO, 2001; ALMEIDA, 2016). A proposição nietzscheana, assim, "evidencia a independência do trágico com relação à forma da tragédia" (MACHADO, 2006, p. 202). Ou seja, independente das tragédias (exceções e catástrofes), haveria uma condição trágica na própria experiência de existir. Em termos conceituais, podemos nos referir a uma "filosofia trágica" conforme a define Clément Rosset (1989a). Por meio de uma "lógica do pior", isto é, a despeito de toda negatividade que a existência possa nos impor, a filosofia trágica tem como premissa a alegria de viver "gratuita", sem objetivos e sem justificativas. Este é o denominador comum que Rosset identifica em pensadores tão dispersos no tempo como os sofistas, Epicuro, Lucrécio, Spinoza, Hume e Nietzsche.

Um dos principais aspectos da filosofia trágica - “[...] a afirmação da incapacidade humana para reconhecer ou constituir uma natureza, donde o caráter vão do pensamento, que não reflete senão suas próprias ordens [...]" (ROSSET, 1989a, p. 104) - consiste na ausência de qualquer princípio "fora do real" que possa ser invocado para compreender o real. É o acaso da existência em sua absoluta indiferença para com a vida, a morte, os acontecimentos e os sentidos todos que atribuímos a eles. Tal indiferença, contudo, não pressupõe falta ou vazio existencial; pelo contrário, parte de uma "plenitude de ser" (ROSSET, 1989a, p. 49) de acordo com a qual nada falta à existência, mesmo ela sendo efêmera, transitória e insignificante.

Assim, a filosofia trágica se diferencia das demais pelo que se propõe: atém-se antes à inocência e crueldade 3 do real do que à sua bondade ou culpabilidade; enxerga acaso e artifício em vez de necessidade e liberdade na natureza; opta pela lucidez, ainda que insignificante, à ilusão das ideias.

É sob essa perspectiva que compreendemos a evolução de O Pequeno Quinquin (2014), na qual os acontecimentos mais extraordinários, como uma sucessão de assassinatos, aparecem sob o signo da indiferença na ordem cotidiana. Desse modo, a série traz à tona não uma imagem do mal, da moralidade ou das dinâmicas sociais, mas antes o encadeamento casual de imagens da indiferença do mundo. Ali, toda "falta" decorre por não-necessidade: falta de sentido da existência (o mundo é fruto do acaso), falta de sentido da vida (nascer e morrer são dados fortuitos, desnecessários) e falta de fundamento da vida social (amoralismo, egoísmo, poder, assimetria social etc. como circunstâncias, convenções). 
Contudo, "não é tempo para filosofar", como adverte o capitão Van Der Weyden ao seu parceiro Carpentier. Afinal, o corpo esquartejado de uma mulher foi encontrado nas entranhas de uma vaca retirada por um helicóptero de um bunker da segunda guerra mundial. No entorno, porém, a pequena cidade na qual a ação se passa segue quase inalterada. Passamos então a acompanhar uma série de crimes tão bizarros quanto violentos, mas que parecem pouco assombrar aqueles que lá vivem.

O Pequeno Quinquin (2014) se divide em dois grupos de personagens: o par de detetives excêntricos que tocam impassíveis a sua investigação e um grupo de jovens garotos locais capitaneados por Quinquin, personagem-título, que mantém uma relação de amizade passional com Eve e alimenta o preconceito contra os imigrantes africanos, que "tentam roubar nossas mulheres".

Em última análise, não existe um assassino na série de assassinatos. Não resta espaço, porém, para lacunas ou mistérios: está claro que o motivo dos assassinatos é racial, temor de toda sociedade francesa apavorada com o crescimento da população muçulmana. Ocorre que esse não é tema central da narrativa, uma vez que toda violência é apresentada e assimilada pelos personagens de maneira mundana, distanciada, tal como um animal pode passar do prazer à fúria ou vice-versa sem se dar conta disso.

A ideia de bestialidade, com efeito, está aqui presente do início ao fim, de modo que os polos do par homem-animal de um lado o homem, cuja boa alma salva, redime, garante a continuidade; de outro, o animal, cuja bestialidade extermina, destrói, dissolve - não podem ser separados. Assim, a animalidade não é apresentada independente da ideia de humanidade (que remete, diga-se de passagem, ao filme $A$ Humanidade, também de Dumont). A bestialidade, de modo análogo, refere-se a aspectos animalescos e, no entanto, é uma característica exclusiva da espécie humana - assim como a tolice, a infantilidade, a insanidade etc. A questão da animalidade é, com efeito, inseparável da questão antropológica.

Atreladas a tal, outras questões poderiam ser identificadas na trama - questões que, se não foram suficientemente abordadas, é porque permanecem marginais em torno do solo trágico em que se assenta o enredo de Dumont. Vejamos, por exemplo, a ideia da "violência vulgar". É bem conhecida a ligação entre violência e sentido como fundação ideológica no processo histórico. Marx (2011) escreveu que os 
grandes fatos da história universal se apresentam duas vezes: primeiro como tragédia, depois como farsa. O pressuposto é que toda ação violenta necessita repetir um modelo, reatualizar um protótipo etc. Para Barthes (1977), por sua vez, as condutas mais violentas são também as mais teatrais, porque na violência haveria sempre um núcleo literário.

No entanto, a violência presente em $O$ Pequeno Quinquin (2014) aparece desatrelada de qualquer sentido, como que seguindo uma vontade cega. Não há nenhum motor oculto ou inconsciente, mas também não se trata de uma caricatura de algo sem mais credibilidade. Trata-se de uma violência vulgar, em que qualquer coisa pode "continuar bem" porque, em vez de unir o sentido a um poder ou a uma lei se acata a dimensão bruta, cega e vulgar da violência. Em uma palavra, sua insignificância.

Do ponto de vista narrativo, por sua vez, é possível identificar certa desconstrução operada por Dumont. Não foram poucos os filósofos, historiadores e críticos do século XX e XXI que trataram do "desaparecimento" da experiência (metanarrativa, personagens exemplares, fatos pesados) como uma angústia de viver fora do presente (Walter Benjamin, Roland Barthes, Giorgio Agamben, Zygmunt Bauman etc.). Não obstante, a ideia fundamental que animou a desconstrução do romance (Henry James, Samuel Beckett, Henry Miller etc.) é justamente a de não narrar fatos, mas mostrar cenas. É o que ocorre na trama de $O$ Pequeno Quinquin (2014): os acontecimentos ficam ou desaparecem na medida em que se impõem a nós como presenças no presente.

Só que na trama em questão essa desconstrução não implica destruição ou anulação da experiência comum; pelo contrário, possibilita afirmar uma experiência de todos (dimensão trágica e irreversível da vida) em detrimento, isso sim, do modelo metafísico que se caracterizaria por remeter, atualizar ou adiar um acontecimento de outros tempos. Não é a primeira vez, nesse ínterim, que Dumont faz uso de "não atores" em seu elenco: pessoas sem virtudes ou atrativos, algumas com estigmas faciais, problemas mentais ou estranhezas físicas. Mas em vez de explorá-las como desvios da normalidade, o diretor as apresenta como indivíduos distintos e ao mesmo tempo comuns - o diferente é normal e o normal é diferente.

Assim, o que de fato reside no cerne da narrativa de Bruno Dumont, aquém das questões levantadas, é o ato de pronunciar-se sem reservas em favor da realidade apresentada, seja ela qual for. É verdade que essa realidade pode parecer um tanto 
enigmática, provocando ao mesmo tempo espanto e humor, bem como os personagens, concomitantemente impenetráveis e plurissignificantes. Ocorre que quaisquer determinações nunca estão fixas: tudo pode inverter-se no seu contrário, porque a própria ambiguidade é mundana, espontânea, casual. Se as personagens são todas desajustadas, tolas, estranhas, é porque não guardam nenhum vestígio do homem moderno, emancipado, senhor de si. E se o real é sem sentido, não o é como efeito da oscilação dos sentimentos ou da razão humana; é a própria noção de sentido que é estranha ao real.

O real é o que aparece, desprovido tanto de sentido quanto de qualquer falta (a falta de sentido, por exemplo), sendo completo em sua insignificância, sem carecer de nada. Num mundo em que a nós, expectadores, tudo o que se passa pode parecer estranho, mas no qual nada é sentido e vivido propriamente como estranho, não há espaço para noções como absurdo ou nonsense. Pois a noção de absurdo como sentido ausente, expectativa frustrada, seria a exceção de uma pretensa ordem racional, normal, harmoniosa, algo que estaria além da compreensão humana, como um território que circunda a racionalidade que constitui a vida cotidiana. Seria como se houvesse uma esfera da razão e, exteriormente, uma esfera do trágico.

Em O Pequeno Quinquin (2014), entretanto, a vida cotidiana é indissociável do dado trágico. A falta de sentido aparece na trama não como indício de absurdo, mas antes como indício da prevalência do acaso, que se repete indiferente ao que quer que seja, dada a não significância de todas as coisas. Essa insignificância do real é tratada por Clément Rosset (2004) como idiotia, no sentido etimológico do termo, ou seja, idiota como simples, particular, único de sua espécie.

Nesse sentido, a noção de "mal" que percorre as desventuras de Quinquin não está diretamente ligada à violência ao menos não à violência como fundadora ou restauradora de um significado social. Ao contrário, o mal em questão é idiota, explicitamente banal, desmistificado e desvinculado de qualquer significado oculto.

Se os velhos conteúdos ideológicos se confundem uns com os outros no decorativismo televisivo francês, isso significa que eles esgotaram sua função histórica, e muito mais incongruente se torna, por isso, a violência que teria a pretensão de reanimá-los. Não havendo mais nada de extracênico pois num elenco declaradamente composto por "não atores", não há representação, apenas apresentação -, dissolve-se a 
estrutura da manifestação e da ocultação, da pureza e da malícia, em proveito da própria cena, que se dá na impossibilidade tanto de escapar do "mal" quanto de compreendê-lo.

Em outros termos, trata-se de "acaso", aquilo que faz acontecer tudo o que acontece, sem qualquer princípio ou fundamento além da própria falta de princípio ou fundamento. Não é que o mundo seja incompleto ou insuficiente (em relação a quê?), é que não há nada que possa nos assegurar que a vida seja regida por qualquer coisa além dela mesma, de modo que ao pensamento cabe menos decifrar o real do que, antes, fazê-lo "falar" por meio de uma sucessão de olhares.

Assim o mal se perpetua no mundo de $O$ Pequeno Quinquin (2014): não como uma revelação repentina, e sim como algo desnecessário e injustificável. Porque o próprio existir é tão desnecessário quanto injustificável; e o indivíduo idiota "não tem argumento algum para invocar em favor da existência, continua perfeitamente incapaz de dizer por que e em vista de que ele vive - e no entanto acha, doravante, a vida indiscutível e eternamente desejável" (ROSSET, 2000, p. 27). Não se trata de um gosto pelo sofrimento, mas de uma conduta afirmativa mesmo diante do pior sofrimento. Mostrar o caos e a dor constitui uma afirmação de força, de vitalidade. Tanto o prazer quanto o sofrimento, afinal, são insignificantes mediante a finitude de uma existência dada ao acaso: eis também a intensidade de sofrer ou deleitar-se.

É dessa conjunção que desponta a perspectiva trágica no pensamento, bem como a idiotia do mal em $O$ Pequeno Quinquin_(2014): "Consolidada a Idiotia, o sujeito trata de afirmar que não há remédios e que a realidade dada não é mais um obstáculo, só é a realidade que se tem, a única, o pior" (OLIVEIRA, 2015, p. 262). O que equivale a "não querer nada de outro modo, nem para diante, nem para trás, nem em toda a eternidade. Não meramente suportar o necessário, e menos ainda dissimulá-lo [...], mas amá-lo" (NIETZSCHE, 1983, p. 374). Assim, os acontecimentos em torno de Quinquin permanecem incógnitos, tal como nossos pensamentos matinais se dissolvem nos gestos apressados ao fim do dia.

\section{Considerações finais}

Encontramos em O Pequeno Quinquin (2014) um material rico para pensar, sob o viés da filosofia trágica, a indiferença do mundo, expressa pelas noções de idiotia e insignificância 
- objetivo a que nos propusemos neste artigo. Como obras que, mais do que nos fazem pensar, pensam junto conosco, os filmes e séries televisivas possibilitam levantar interpretações não atreladas necessariamente ao discurso, implícito ou explícito, enunciado na tela. No âmbito de um estudo fílmico, com efeito, levamos a cabo o que se pode designar por "hermenêutica trágica":

[...] se tudo pode ser interpretado, é precisamente porque não há o que ser interpretado - sendo um dos aspectos do trágico "o que se furta a toda tentativa de interpretação". [...] Com efeito, por "hermenêutica trágica" devemos entender apenas uma hermenêutica que, como a de Ricoeur, não pressupõe um conteúdo específico a ser interpretado, mas que, em vez disso, encare o compreender como um modo de ser (BECCARI, 2016, p. 101).

Desse modo, na lida com a série selecionada - O Pequeno Quinquin (2014) -, não se buscou uma leitura crítica, histórica ou puramente estética. Também não houve a "aplicação" um método de análise, pois fizemos da própria narrativa elencada um caminho para pensarmos/interpretarmos/ analisarmos o problema posto em questão: o modo como a idiotia e a insignificância expressam, à luz do pensamento trágico, certa indiferença do mundo.

Cumpre abreviarmos, então, aquilo que poderia aludir a um "resultado" de análise: a idiotia e a insignificância se manifestam em $O$ Pequeno Quinquin não como uma exceção à normalidade, como se o absurdo (falta de sentido) escapasse à ordem do mundo, mas como a expressão do mundo humano. Afinal,

Em um mundo plenamente humano, tudo é esperado. E, nessa espera, mentira e blefe são reconhecidos e incorporados ao jogo. É por isso que quase todos os tipos humanos são possíveis no âmbito desse mundo, servindo a qualquer contexto, como neuróticos, esquizofrênicos, cegos, loucos etc., desde que, no contexto, não se mostrem estrangeiros a esse desvio, um desvio esperado (OLIVEIRA, 2015, p. 258).

É justamente o que ocorre com o par de investigadores em confluência com o mundo das crianças capitaneadas por Quinquin. Cumprem seu papel sem a menor expectativa à verdade. No caso, pouco importa o(a)(s) assassino(a)(s), pouco 
importa a motivação, a crueldade, a violência, o mal. Aniquiladas as diferenças - o que é bestial, o que é humano, o que é inumano - tudo se apresenta pleno e acabado. E as ações seguem o fluxo da idiotia, da singularidade irrepetível da existência.

\section{NOTAS}

1. Cf., por exemplo, o estudo de Jan Olsson (1999) sobre os elementos da cultura sueca que influenciaram as técnicas de sincronização entre som e imagem do cinema sueco em meados do século XX.

2. Ou "diante" dele, nos termos do filósofo Paul Ricoeur (2008, p. 68): "Esta proposição não se encontra atrás do texto, como uma espécie de intenção oculta, mas diante dele, como aquilo que a obra desvenda, descobre, revela”.

3. "Cruor, de onde deriva crudelis (cruel) assim como crudus (cru, não digerido, indigesto) designa a carne escorchada e ensanguentada: ou seja, a coisa mesma privada de seus ornamentos ou acompanhamentos ordinários, no presente caso a pele, e reduzida assim à sua única realidade, tão sangrenta quanto indigesta. Assim, a realidade é cruel - e indigesta - a partir do momento em que a despojamos de tudo o que não é ela para considerá-la apenas em si-mesma [...]" (ROSSET, 1989b, p. 18).

\section{Referências}

ALMEIDA, Rogério de. O eterno retorno do trágico: sua condição contemporânea. In: LIMA, Alessandra Carbonero; PAGOTTO-EUZEBIO, Marcos Sidnei; ALMEIDA, Rogério de (Org.). Antiguidades Contemporâneas: XXII Semana de Estudos Clássicos da FEUSP. São Paulo: Faculdade de Educação da USP, 2016. p. 111-127.

BARTHES, Roland. Roland Barthes por Roland Barthes. Tradução Leyla Perrone-Moisés. São Paulo: Cultrix, 1977.

BECCARI, Marcos. Articulações Simbólicas: uma nova filosofia do design. Teresópolis, RJ: 2AB, 2016.

BORDWELL, David. La narración en el cine de ficción. Barcelona, Buenos Aires, México: Paidós, 1996.

CRUCHINHO, Fausto. A televisão de Roberto Rossellini. Estudos do Século $X X$. Coimbra: Imprensa da Universidade de Coimbra, n. 7, p. 319-335, fev. 2007. Disponível em: < http:// hdl.handle.net/10316.2/36713>. Acesso em: 26 fev. 2017.

FASSBINDER, Rainer Werner. O Anarquista da Fantasia. Rio de Janeiro: Jorge Zahar, 1988.

HIERRO, Rafael Del. El saber trágico: de Nietzsche a Rosset. Madrid: Ediciones del Laberinto, 2001.

IMDB. O Pequeno Quinquin. Website. 2014. Disponível em: <http://www.imdb.com/title/tt3053694/>. Acesso em: 26 fev. 2017. 
LANLO, Jean-Marie. Appréciation: Le changement dans la continuité. Séquences: La revue de cinema. Website. 18 fev. 2015. Disponível em: <http://www.revuesequences. org/2015/o2/ptit-quinquin/>. Acesso em: 26 fev. 2017.

MACHADO, Roberto. O Nascimento do trágico: de Schiller a Nietzsche. Rio de Janeiro: Jorge Zahar, 2006.

MARX, Karl. O 18 Brumário de Luís Bonaparte. São Paulo: Boitempo, 2011.

NIETZSCHE, Friedrich. Obras incompletas. Tradução Rubens Rodrigues Torres Filho. São Paulo: Abril Cultural, 1983. (Col. Os Pensadores).

OLIVEIRA, Louis José Pacheco. Por uma reapropriação da ideia de homem. 2015. $307 \mathrm{f}$. Tese (Doutorado em Educação) - Faculdade de Educação da USP, Universidade de São Paulo, São Paulo, 2015.

OLSSON, Jan. In and out of Sync: Swedish Sound Films 19031914. Film History. Luton: University of Luton Press, v. 11, n. 4, fev. 1999.

P'TIT QUINQUIN. Bruno Dumont. França: 3B Productions/ Arte France/Pictanovo Nord-Pas-de-Calais/Région Nord-Pas-de-Calais/Le Fresnoy Studio National des Arts Contemporains/CNC/Cofinova 10/TV5 Monde, 2014.

REIABAPTISTA, Vítor. Estudos Fílmicos: o estado da Arte (e da Ciência). Livro de Actas - 4o SOPCOM. Faro: Universidade do Algarve, p. 1029-1033, jun. 2005. Disponível em: $<$ http://www.bocc.ubi.pt/pag/baptista-vitor-estudos-filmicos-estado-arte.pdf $>$. Acesso em: 26 fev. 2017.

RICOEUR, Paul. Hermenêutica e ideologias. Petrópolis: Vozes, 2008.

ROSSET, Clément. A lógica do pior: elementos para uma filosofia trágica. Rio de Janeiro: Espaço e Tempo, 1989a. . Alegria: a força maior. Rio de Janeiro: Relume-Dumará, 2000.

Le réel: traité de l'idiotie. Paris: Les Éditions de Minuit, 2004.

. Princípio de crueldade. Rio de Janeiro: Rocco, 1989b.

SOARES, Maria da Conceição Silva. O audiovisual como dispositivo de pesquisas nos/com os cotidianos das escolas. Visualidades,Goiânia, v. 14, n. 1, p. 80-103, jan./jun. 2016.

XAVIER, Ismail (Org.). A experiência do cinema: antologia. Rio de Janeiro: Edições Graal, 1983. 
Recebido em: 25/02/2017 Aceito em: 01/12/2017 


\section{ROGÉRIO DE ALMEIDA}

rogerioa@usp.br

Professor Associado da Faculdade de Educação da Universidade de São Paulo (FEUSP). Coordena o Lab_Arte (Laboratório Experimental de Arte-Educação e Cultura) e o GEIFEC (Grupo de Estudos sobre Itinerários de Formação em Educação e Cultura). É Editor da Revista Educação e Pesquisa (FEUSP) e Editor Colaborador para a área de Educação da Revista Machado de Assis em Linha. Bacharel em Letras (1997), Doutor em Educação (2005) e Livre-Docente em Cultura e Educação, todos os títulos pela Universidade de São Paulo (USP). Pós-Doutoramento na Universidade do Minho (2016). Trabalha com temas ligados a Cinema, Literatura, Filosofia Trágica e Imaginário. Site: <http://www.rogerioa.com/>

\section{MARCOS BECCARI}

contato@marcosbeccari.com

Doutor em Educação pela Faculdade de Educação da Universidade de São Paulo (FEUSP), Graduado em Design Gráfico e Mestre em Design, ambos pela Universidade Federal do Paraná (UFPR). Professor do Departamento de Design e do PPG-Design da UFPR. Pesquisador nos grupos: Navis - Núcleo de Artes Visuais (UFPR e Unespar), Design Colaborativo e Cocriação (UFPR), Geifec - Grupo de Estudos sobre Itinerários de Formação em Educação e Cultura (USP) e Lab_ Arte - Laboratório Experimento de Arte-Educação e Cultura (USP).

\section{CESAR ZAMBERLAN}

cesar.zamberlan@gmail.com

Doutor em Estudos Comparados de Literaturas de Língua Portuguesa pela FFLCH USP, mestre em Literatura Brasileira pela FFLCH USP, graduado em Jornalismo pela Faculdade de Comunicação Social Cásper Líbero e em Letras pela FFLCH USP. É professor da Faculdade de Letras, Artes, Comunicação e Ciências da Educação da Universidade São Judas Tadeu (SP), pesquisador do GEIFEC (Grupo de Estudos sobre Itinerários de Formação em Educação e Cultura) da Faculdade de Educação da USP, pesquisador das relações entre Literatura e Cinema (adaptações e questões de linguagem), redator da Revista Interlúdio (http://www.revistainterludio.com.br/), e membro da Associação Brasileira dos Críticos de Cinema. 